\title{
Black Currant Juice
}

National Cancer Institute

\section{Source}

National Cancer Institute. Black Currant Juice. NCI Thesaurus. Code C158098.

The juice from the berries of the black currant (Ribes nig rum L.) shrub belong ing to the family Grossulariaceae, with potential antioxidant and protective activities. Black currant juice contains a variety of nutrients, including vitamin C, iron, potassium, manganese, anthocyanins, including delphinidin-3-O-glucoside, delphinidin-3-O-rutinoside, cyanidin-3O-glucoside, and cyanidin-3-O-rutinoside. The antioxidants in black currant juice scavenge free radicals, thereby protecting cells from damage. 